\title{
Advances and Breakthroughs in Titanium forgings for critical structural parts
}

\author{
J.Lecadet $^{1}-$ R.Forestier ${ }^{2}-$ P.Delaborde ${ }^{3}$ \\ ${ }^{1}$ R\&D Director ERAMET High Performance Alloys Division (Aubert \& Duval, Les Ancizes - France) - ${ }^{2}$ Metallurgical \\ Department (Aubert \& Duval, Pamiers - France) - ${ }^{3}$ EcoTitanium, (Saint-Georges de Mons - France)
}

\begin{abstract}
$\underline{\text { Abstract }}$
Assuming the high level of properties and reliability of titanium forgings, strong drivers of research and development for forgings are the pressure on cost, the buy to fly ratio reduction and the life cycle. This presentation discusses the potential of optimizations to address these challenges. The first way to concretely answer the question of the cost and of the life cycle is the recycling of manufacturing scrap and end-of-life products, using the concept of circular economy and implementing a short loop from end user to melters. This is a considerable opportunity to mitigate the risks related to the supply of primary material and to the erratic fluctuations of raw material prices.
\end{abstract}

The second step to optimize both the added value and the material consumption consists in adapting accurately the melting and ingot conversion processes to the actual needs of the application and the subsequent transformation processes.

Considering the close die forging step, the use of the concept of Design for forging has also a great potential to optimize the cost and the functions of the forgings. Near Net Shape Forging of titanium, using high temperature close die forging is a great opportunity to make a breakthrough in terms of buy to fly ratio. In addition to all these improvements, the use of high-power hydraulic presses is a key element to take full advantage of them and to manufacture large critical parts with more functions.

All together these levers could provide drastic cost reductions, and a considerable reduction in the environmental impact, keeping the advantages of titanium forgings in terms of metallurgical integrity, residual stresses and properties. The implementation of these improvements will require continuous efforts of development from the whole titanium supply chain, and collaboration between integrated titanium forgings suppliers and the OEMs.

\section{Introduction}

Titanium forgings have significant intrinsic technical advantages for large and safety critical airframe components, in terms of reliability and properties tradeoff. These properties are quite adequate presently and in the coming years most of advancements in aerospace structures will be driven mainly by the manufacturing and life cycle cost pressure.

In order to face these challenges a first answer of the supply chain is the consolidation of the actors, allowing the emergence of integrated manufacturers managing all the processes, from melting to machining of titanium components.

In this paper we'll describe how an integrated supply chain, such as the one developed by Aubert \& Duval, allows addressing the main levers [1] to give appropriate answers to the cost and environmental challenges of titanium parts manufacturing:

- Implementation of circular economy to recycle manufacturing titanium scrap and end of life titanium parts.

- Melting and conversion adaptation to reduce cost and material losses in the earlier steps of the manufacturing process.

- Near net shape forging of Ti64 airframe components using high temperature $\beta$ close die forging.

- Design to forging concept implementation to optimize forgings blanks, to integrate more functions thanks to high power presses, and to introduce hybridation of forging process with additive manufacturing such as Direct Energy Deposition processes (DED) or new welding technologies.

\section{$\underline{\text { Aubert \& Duval integrated supply chain }}$}

Following several decades of experience in titanium close die forging of structural parts, Aubert \& Duval has implemented during the last five years a fully integrated manufacturing process. Today all this process is now qualified and covers all the manufacturing steps (figure 1). 


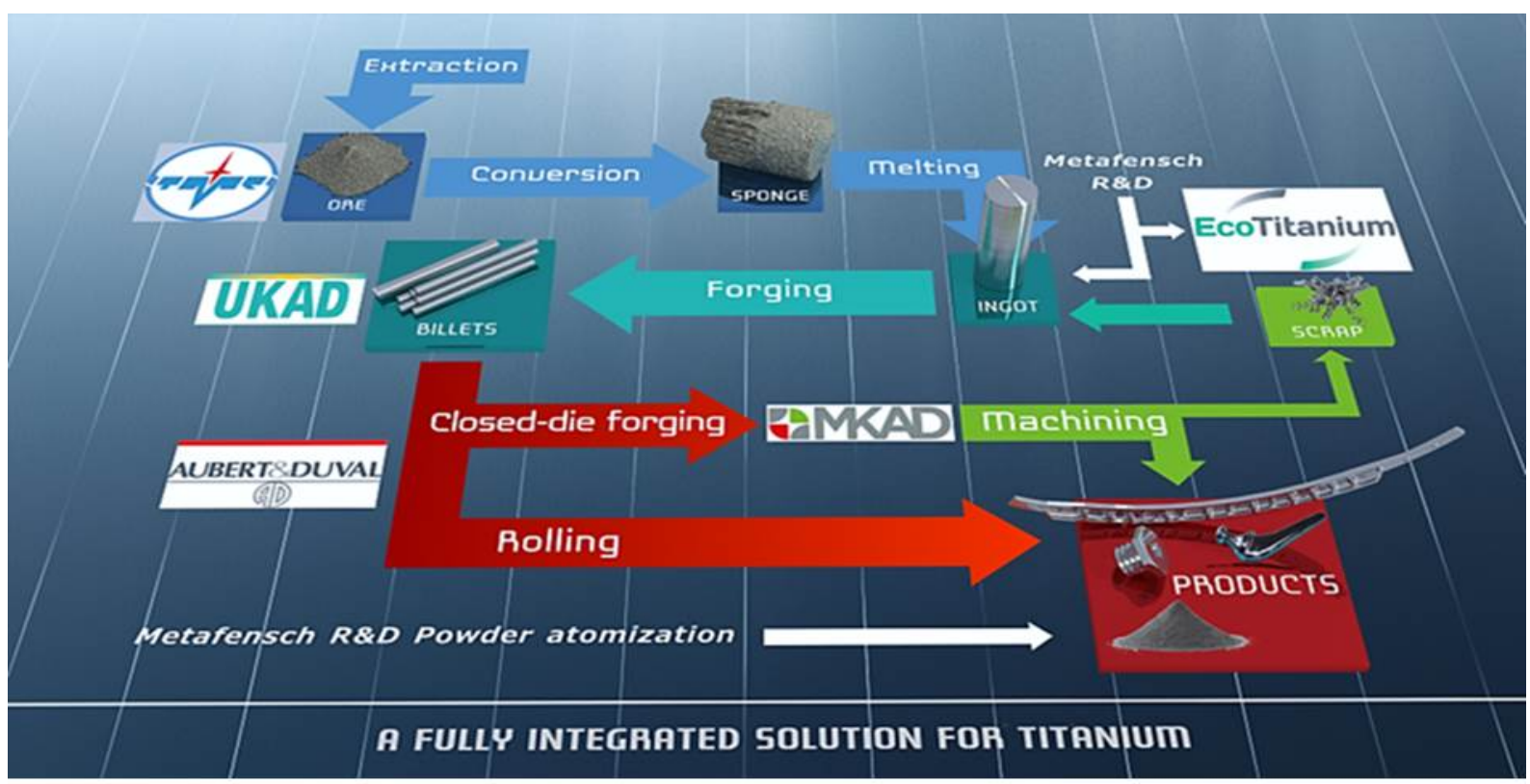

Figure 1: Aubert \& Duval Titanium Integration

\section{Melting and recycling at EcoTitanium}

EcoTitanium is a company that was created in 2014 by three shareholders: UKAD, ADEME (the French Environment \& Energy Management Agency), Credit Agricole Centre France.

Aubert \& Duval is the industrial operator of EcoTitanium through UKAD, a joint venture created by Aubert \& Duval and UKTMP to develop a billetizing unit in France at Saint-Georges de Mons, close to Aubert \& Duval plants.

EcoTitanium is a facility dedicated to titanium recycling aiming at producing aeronautical quality titanium grades. The main piece of equipment is a Plasma Cold Hearth Crucible furnace (PAMCHR) which has the capacity to melt both massive scrap and turnings after preprocessing. A subsequent Vacuum Arc Remelting step (VAR) is also performed by EcoTitanium to cover all the aeronautical specifications. The green field plant of EcoTitanium built next to UKAD facility was commissioned in mid-2017 and is now completing its ramp up.

\section{Ingot conversion at $U K A D$}

Aubert \& Duval is also in charge of the industrial operation of UKAD. The main piece of equipment of UKAD is an open die forging hydraulic press, designed to optimize the titanium ingot conversion process. This plant was commissioned in 2011 and now UKAD can supply Aubert \& Duval with billets optimized in terms of characteristics or geometry. Scrap produced at this first transformation step can be processed with a short recycling loop by EcoTitanium.

\section{Close Die Forging in Aubert \& Duval plants}

Aubert \& Duval is operating close die forging hydraulic presses in its plants of Issoire and Pamiers, with a wide range of capabilities and power (from 20000 to 65000 tons). These diversified means allow optimizing the processes and the tradeoff between operating cost, material yield and components characteristics.

\section{Machining at MKAD}

MKAD is a joint venture developed by Aubert \& Duval and Mecachrome to perform the machining of large titanium structural parts. This plant was commissioned in 2016 and produces machined forged parts ready for assembling by the OEMs. It is also the last link of the chain to collect and to recycle the turnings and the reverts produced by the manufacturing of the parts.

To conclude we can observe that two major advantages are behind this integrated supply chain of titanium parts: The optimization of intermediate products and the recycling of material with a short loop. We will see later in this paper how this can be beneficial for the entire production chain and end customers.

\section{Circular Economy: Short loop recycling and integration}


The high buy to fly ratio of titanium forgings is shown as a drawback due to the cost of aeronautic quality titanium grades, but this is without considering the intrinsic value of high quality scrap that can be recovered through a short recycling loop.

Considering a full integration of scrap recycling to produce double melt titanium ingots, the theoretical material balance shows that maximum recycling rate close to $80 \%$ is possible with average buy to fly of 10 (figure 2). This maximum is compatible with the technical constraints of scrap melting, requiring a minimum amount of sponge introduction. We can also notice that this maximum rate is not so much affected by lower buy to fly ratios (figure 3a). Moreover if we consider that recycling is fully integrated within the manufacturing process we can define the minimum consumption of virgin raw materials and compare this amount to the weight of machined parts. This comparison can be expressed as a "buy to fly ratio on virgin raw materials", which is quite lower than the usual buy to fly ratio comparing billets weight to machined parts weight (figure $3 \mathrm{~b}$ ).

This "buy to fly ratio on virgin materials" is quite relevant if we consider the reduction of the environmental impact of titanium used for aerospace. In particular the impact of reducing energy consumption is very significant, as the energy consumption to produce recycled ingots, incorporating about $20 \%$ of sponge, represents only one fourth of the energy consumption to produce primary ingots [2] [3].

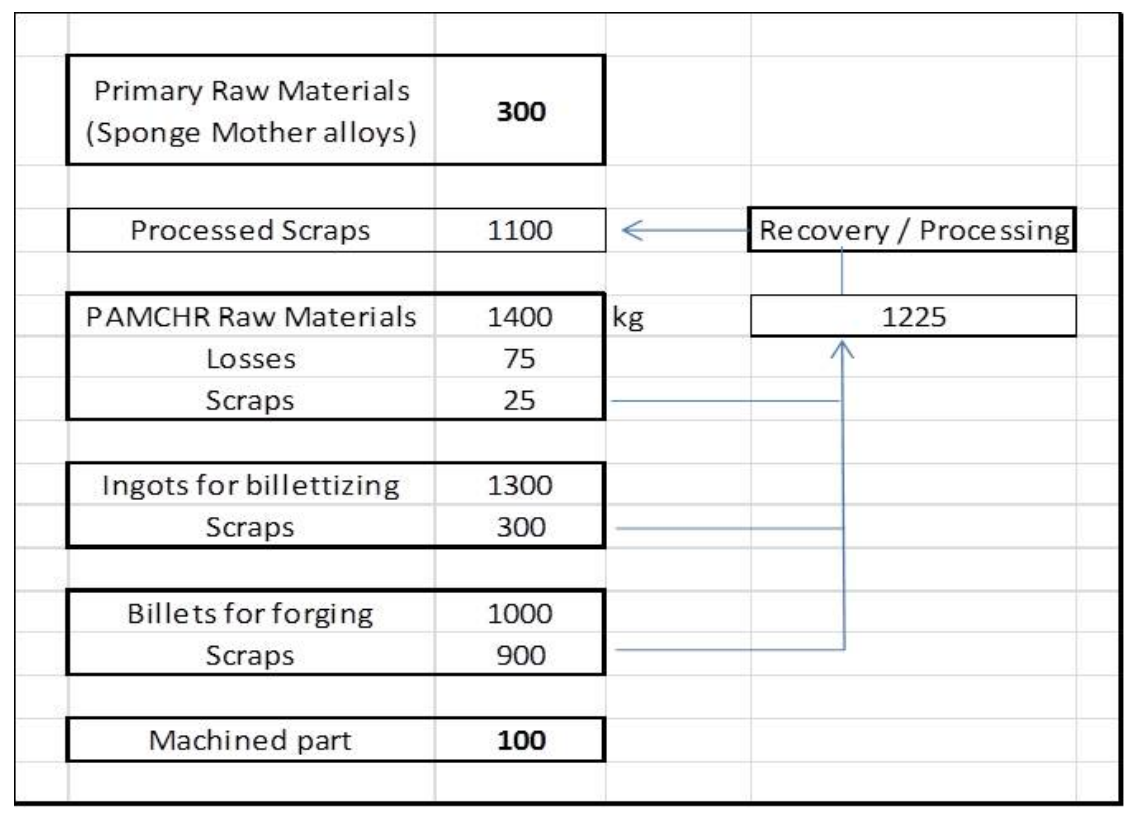

Figure 2: Simplified material balance of parts manufacturing with typical buy to fly of 10 and maximum recovery yields
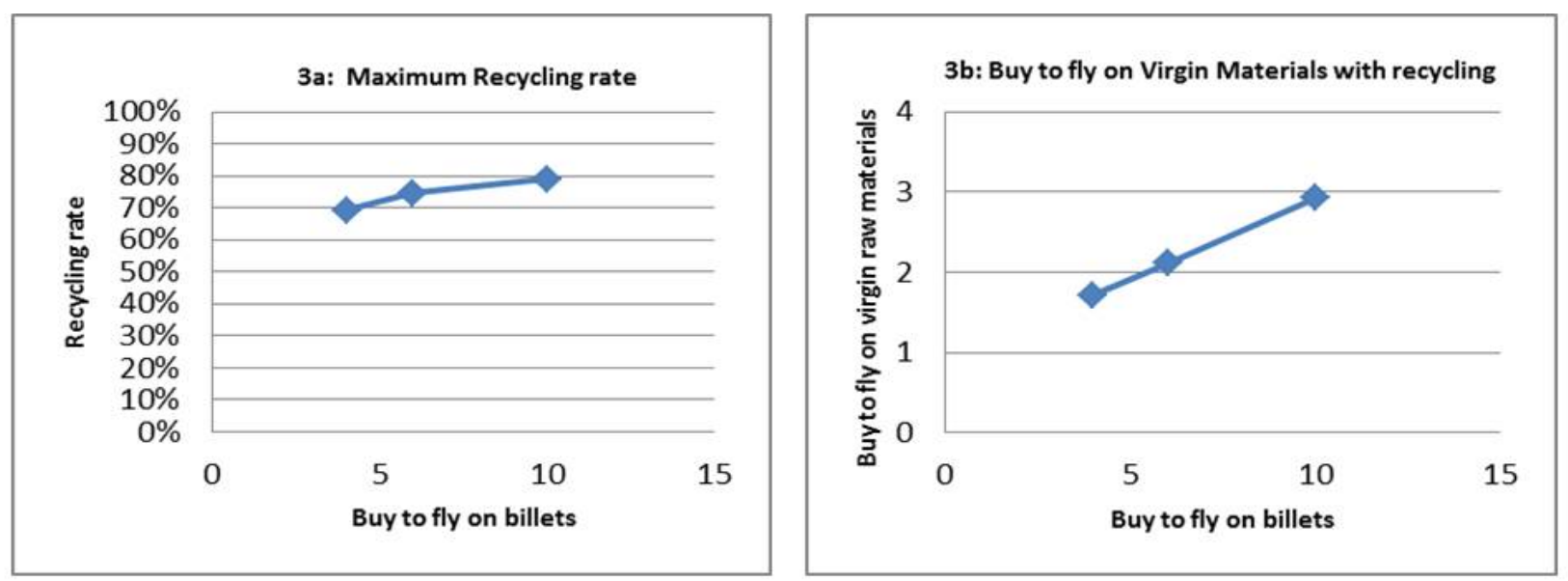

Figure 3: Influence of Buy to fly ratios on maximum recycling rate (3a) and on Virgin raw materials buy to fly (3b) 
So Recycling of titanium scrap will remain a key aspect of titanium economy whatever the improvement on transformation processes are, in terms of sustainable development and as the cost of billets can be reduced when using the manufacturing scrap in circular economy (figure 4). This reduction of the billet cost is recovered in the material cost of the machined components (figure 5a), and recycling considerably reduces the variations linked to the price of raw materials (figure $5 b$ ).

The "price" of scrap is of course an important parameter to assess the cost advantage of ingots or billets using recycled materials (figure 4). In the case of a recycling loop that is "open" i.e. involving separate actors of the supply chain, solid scrap are valorized at the market price. For integrated supplier it is possible to implement an actual circular economy, and to valorize the produced scrap with a minimum and constant value, not correlated to sponge price.

To go further it is necessary to look at the impact of these various models of scrap valorization on the parts cost after machining. For that purpose we consider only the material value contained in the final parts, assuming a buy to fly ratio (from billet to machined part) of ten. This material value is the cost of the billet minus the value of the scrap (solid and turnings) produced along the manufacturing process.

The result of this simple model confirms a reduction on the material cost in the final components by recycling manufacturing scrap (figure 5a) with an advantage for the "circular economy" model. This is achieved despite the lower valorization of the scrap in circular economy which lowers the recovery of the value with scrap along the manufacturing process. Nevertheless we have to stress the fact that the lower and constant valorization of scrap, which is possible with an integrated circular economy, is quite important in terms of working capital and to mitigate the risks related to sponge cost variations (figure $5 \mathrm{~b}$ ). These advantages are decisive for an integrated scheme.

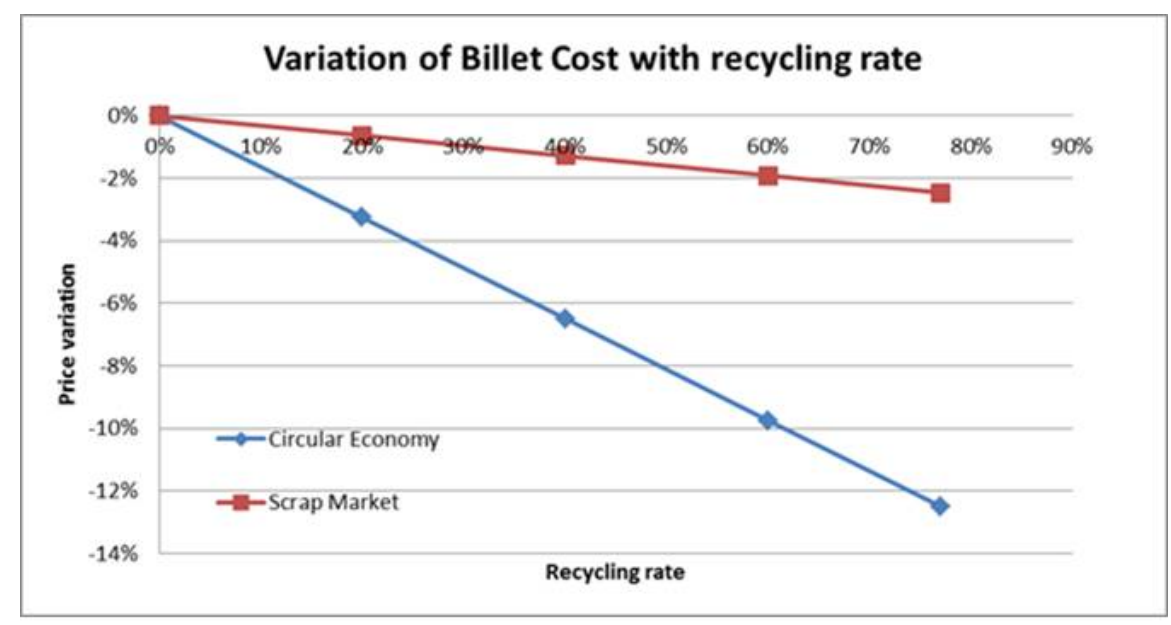

Figure 4: Evolution of billet cost with scrap rate in the ingot (for two hypothesis of scrap valorization) 

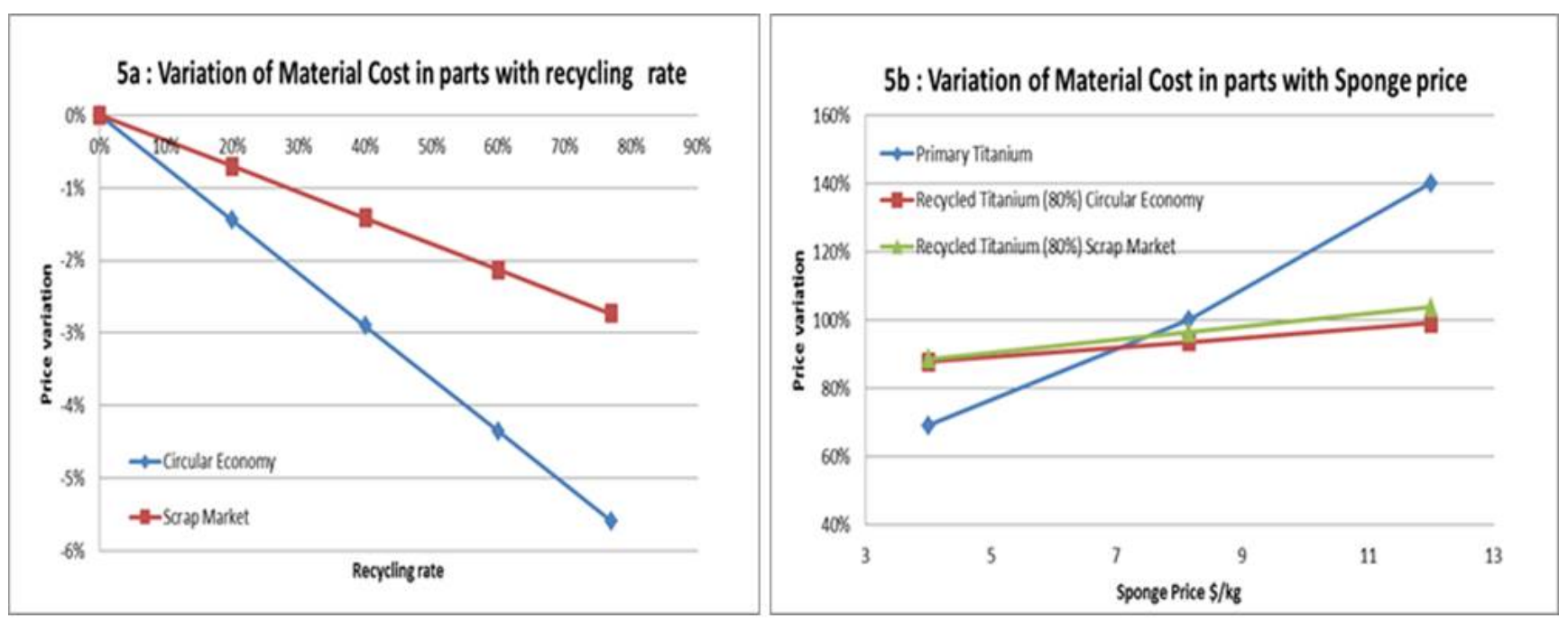

Figure 5: Evolution of material cost in parts

\section{Melting and conversion: tailor-made optimizations}

For titanium airframe manufacturing the main objectives and advantages of the melting and billetizing steps are to supply close die forging with a material having a controlled chemical composition and microstructure, a controlled quality allowing avoiding subsequent NDT in the volume of the parts, and geometry suitable to optimize the preforms.

But today we are still at the beginning of a complete integrated optimization that could take into account the entire close die forging process needs and the right level of quality for the applications. For instance do we need globularized Ti64 microstructures for parts that are $\beta$ treated during their close die forging process?

A first potential for simplification and cost reduction of Ti64 billets concerns the melting process with the PAMCHR. In other papers of this conference presenting the PAMCHR modelling [4] [5] we can observe that this process has several intrinsic advantages to provide titanium grades for aero structures, without subsequent VAR operation:

- PAMCHR process is lowering segregation in comparison with segregation observed using Vacuum Arc Remelted (VAR) process,

- PAMCHR process has a good mixing capability and a good ability to provide homogenous Ti64 ingots provided that a good raw materials preparation is achieved,

- PAMCHR process allows promoting refining of the alloy thanks a higher residence time achieved in the refining crucible.

The macro and microstructures observed in PAMCHR material are quite satisfactory, and for some aspects even better than those achieves with VAR (figure 6). The possible porosities in the ingots induced by the gas atmosphere of the PAMCHR process are small enough to be managed by the billetizing process. So it seems quite possible to use single PAMCHR ingots instead of PAMCHR \& VAR ingots to supply titanium alloys for airframe applications. On top of the cost reduction obtained with recycling in PAMCHR this could give an additional gain of about $10 \%$ of the total cost of the billet.

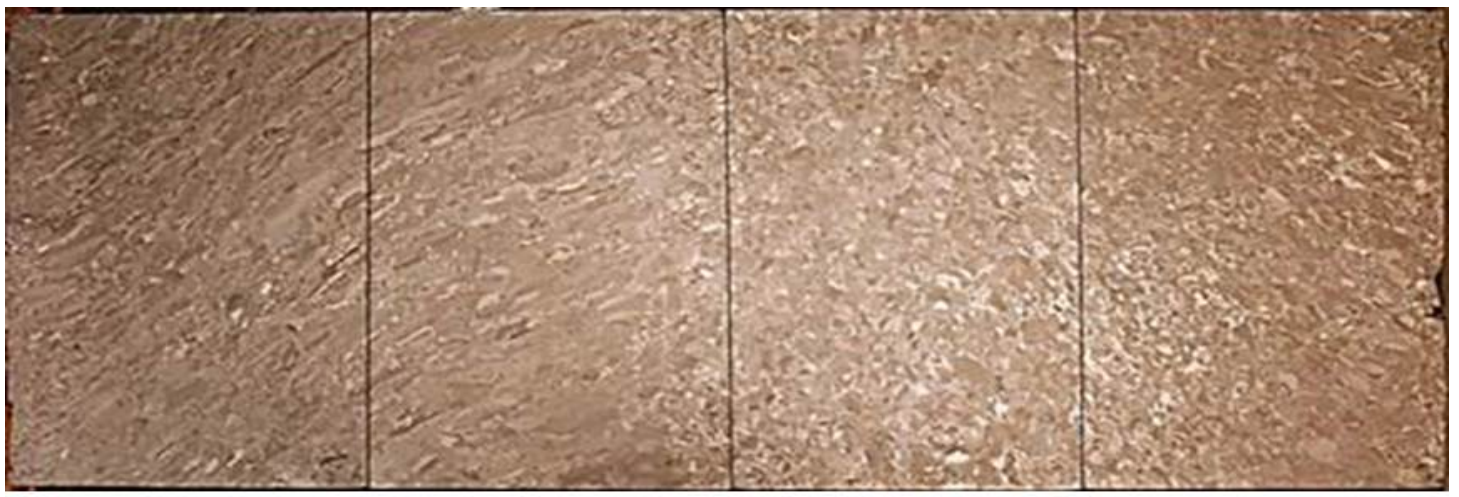

Figure 6: Macrostructure of as cast PAMCHR ingot

A second potential of simplification and cost reduction to produce Ti64 billets is based on the conversion process. For application using $\beta$ treated Ti64 it seems quite realistic to simplify the present process that is aiming at producing a globular microstructure of 
the $\alpha / \beta$ phase. The forging sequence of upsetting and drawing below the $\beta$ transus to obtain such a microstructure can be simplified without hindering the subsequent UT of the billet.

\section{Near Net shape forging of Ti64 airframe components}

Beyond the optimization of the billet cost, the reduction of the buy to fly ratio of the blanks before machining has the greatest impact on the cost of the finished parts, because it concerns major costs at the end of the value chain. To reduce this buy to fly ratio from billets to machined forged parts, the Near Net Shape Forging of Ti64 appears to still have great potential. The concept used here is that of the high temperature forging of the material stock, above $\beta$ transus temperature. This process allows reducing the flow stress during forging operation (figure 7).
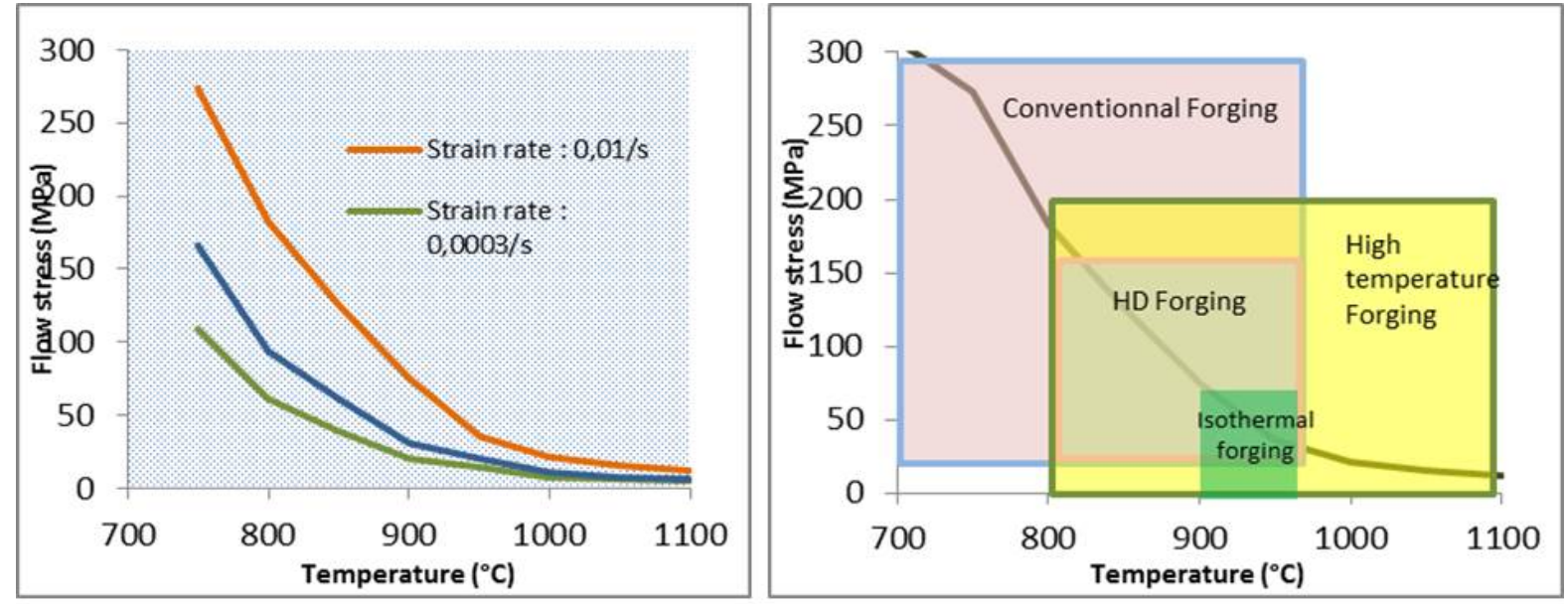

Figure 7: Flow stress of Ti64 [7] and high temperature forging area

This reduction of the flow stress allows to reduce drastically the thickness of ribs and webs in closed die forged parts. This technique is usefull for the closed die forging of very large parts, which necessitates powerfull closed die forging presses. It can also be used for smaller parts, in order to optimize the buy to fly ratio. All together the buy to fly ratio can be reduced by about $30 \%$ [6] in comparison to typical buy to fly ratio, and probably more for more complex parts presenting difficulties to fill the material in dies.

Beyond this advantage on buy to fly ratio we can notice also that this process can permit to perform the closed die forging with one heat, and to reduce very significantly the machining time. Thus we can conclude that added costs can be reduced as well. Finally, the potential cumulative gains resulting from the reduction of the buy to fly ratio are of the order of $30 \%$

This process can be used when $\beta$ annealing is required after closed die forging, in order to improve toughness [7]. This process is widely used for $\beta$ titanium alloys. Under certain deformation conditions, Ti64 may fully recrystallize after annealing, giving a fully equiaxed microstructure (figure 8 ). In that case, the mechanical properties are very similar to those obtained through a classical $\alpha / \beta$ closed die forging process followed by a $\beta$ solution treatment.
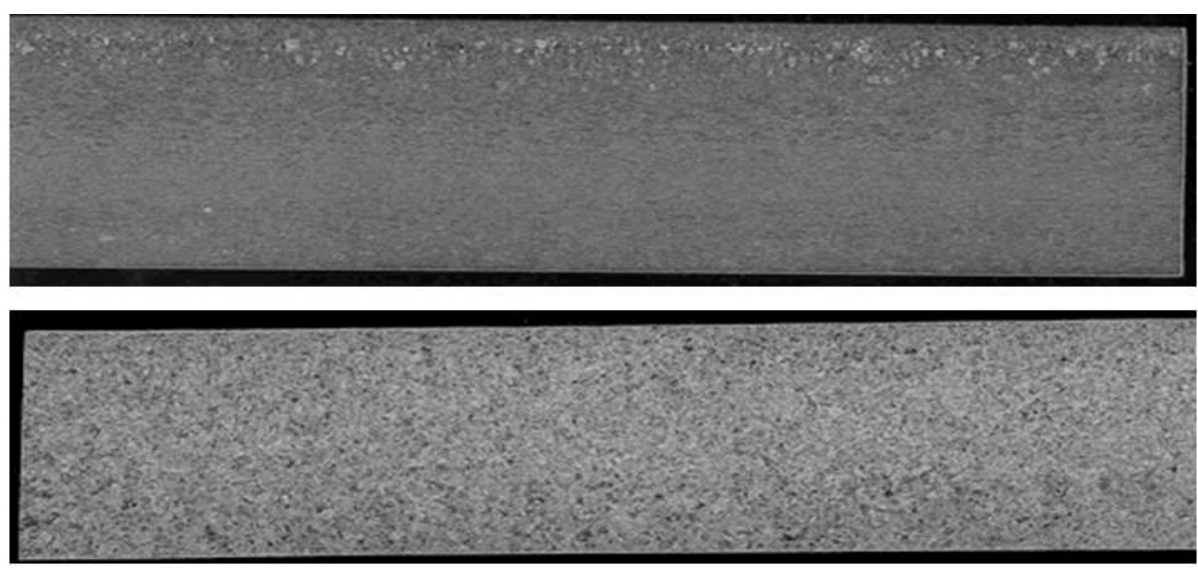

Figure 8: Microstructures of $\beta$ forged part before (up) and after (down) $\beta$ solution treatment (Aubert \& Duval) 
Some research work still have to be performed to fully assess the microstrucutral evolution, and to specify all the relevant parameters for the material resulting from this process. This would result in the development of this technique for more components.

\section{Design to forging implementation}

The Design for Manufacturability concept is the process of designing a product in order to facilitate the manufacturing process and to reduce its costs. Potential manufacturing difficulties or extra costs can be fixed with an integrated and optimized solution during the design phase. The concept of Design for Manufacturing, or Design for forging in the present case, has also a great potential to optimize the functions of the forgings.

More precisely we can assume that the design to forging concept implementation is key:

- To adapt the design of the parts to the forging process by optimizing the material distribution.

- To integrate more functions in one part

This approach can also be necessary to develop new processes as for instance the hybridation of forging and additive manufacturing. Hybridation means here that we are using both forging and additive manufacturing in the process to produce large airframe components. This hybridation can be used to optimize the design of blanks prior closed die forging and to add functions in these blanks or in the final components. As the properties and microstructures can be affected locally with such practice an accurate assessment of the component design and specification as to be reviewed to take into account the possible discrepancies and heterogeneities in the material.

Thus it seems obvious that this approach of design to forging requires a close cooperation of engineering teams to better manage the constraints of both design and manufacturing.

\section{Conclusion}

We have described in this paper several levers showing clearly that some drastic improvements and cost reductions can be performed all along the manufacturing process of forged airframe components. If all the manufacturing steps of titanium airframe components are integrated, from melting to machining, a potential of about $40 \%$ of savings can be identified both in terms of buy to fly ratio and in terms of added costs. In addition the use of these improved processes in combination with high power hydraulic presses could allow to integrate more functions in forgings and to minimize assembling.

The implementation of such progress will require more integration of titanium forging suppliers in order to optimize globally all the manufacturing process, from melting to machining. More over the full optimization will require collaborative research with multidisciplinary consortium, including OEMs, integrated forgings suppliers, research institutes and academic.

\section{$\underline{\text { References }}$}

[1] D. Sanders - Titanium manufacturing processes and Alloys selection for aerospace applications - International Titanium Association Conference - Atlanta, 2012

[2] US Department of Energy, Office of Energy Efficiency \& Renewable Energy, Advance Manufacturing Office - Bandwidth Study on Energy Use and Potential Energy Savings Opportunities in U.S. Titanium Manufacturing- September 2017

[3] E. Drezet - Le Recyclage des Métaux - Eco Info 2014/09/03

[4] E.Doridot, S.Hans, A. Jardy, JP. Bellot. Industrial applications of modelling tools to simulate the PAMCHR casting and VAR process for Ti64, Titanium 2019, Nantes

[5] L.Décultot, A.Jardy, S.Hans, E.Doridot, J.Delfosse, F.Ruby-Meyer, JP. Bellot. Characterization of the thermal flux transferred by the plasma arc to the surface of the liquid bath in the Plasma Arc Melting Cold Hearth Refining process (PAMCHR), Titanium 2019, Nantes

[6] T.Witulski, G.Terlinde, G.Fischer - Development of low cost Near Net Shape forgings from Ti6-4 by special process technology - Ti-2003 Science and Technology - Hamburg, 2697-2704.

[7] G. Lutjering, J. C. Williams, Titanium, $2^{\text {nd }}$ Edition, Springer, 2007. 